\title{
Volatility of Ship Demolition Index Prices
}

\section{Bangar Raju Totakuraa, Vrinda Sharmaa, Vishal Kashava, Subir Ranjan Das ${ }^{b}$}

Aim: The main objective of this paper is to explore the volatility of ship demolition indices. Ship demolition indices are becoming increasingly important owing to the growing number of norms and rules imposed by the International Maritime Organization. Financial crunch and stricter emission norms are forcing vessel owners to consider ship demolition options. This study examines the volatility of ship demolition rates of the Baltic Demolition Index and the causal relationship between the Chinese and Indian subcontinent indices.

Methods: EGARCH models have been used to explore the volatility and asymmetric effects in the time series. The relationship between the two indices was established using the Granger causality test.

Results and conclusion: The final analysis confirmed that ship demolition indices are both volatile and asymmetric. This study is unique and useful to ship owners, vessel operators, and banks as it helps them understand the risks involved.

\section{KEY WORDS}

$\sim$ Causality

$\sim$ Volatility

$\sim$ EGARCH

$\sim$ Baltic demolition index

a. University of Petroleum and Energy Studies, Dehradun, India

e-mail: bangarraju@gmail.com

b. Sharda University, Greater Noida, India

e-mail: subir.das@sharda.ac.in

doi: 10.7225/toms.v10.n02.w04

This work is licensed under (cc) BY

Received on: 07.06.2020/Revised on: 27.02.2021 / Accepted on: 26.07.2021/Published online: 09.08.2021

\section{INTRODUCTION}

Shipbreaking is the disassembling of old ships to recover steel scrap and different materials. The ship-breaking industry is a reusing industry that recovers steel from ships or, in other words, $90 \%$ of the vessels. Other materials, comprising the remaining $10 \%$, are machines and gear, furniture and fittings, asbestos, wood boards, oil, synthetic substances, electrical fittings, and so on. Ship-breaking practices, originally reserved for high-income nations, have gradually also been adopted by low-income nations with their raising awareness of environmental concerns and the consequent introduction of more stringent controls. In the course of that process, the ship-breaking industry has transformed from a capital-serious sector to a work-escalated industry. The ship demolition or shipbreaking industry is important due to its major effect on ship supply and demand, as it affects freight rates on both freight shipping and shipbuilding markets. The need to understand the said demolition markets is of critical importance. Although the shipbreaking industry has the potential for financial development, it also brings the additional risks of different national regulations. Until the 1970s, ship breaking practices have largely been concentrated in the newly created nations. Nations like India, Bangladesh, China and Pakistan have less stringent labor standards or less effective enforcement of labor regulations. The data from (UNCTAD, 2019) illustrate ship demolition trends over the last 4 years.

Figure 1 shows continuous ship demolition growth at the global level until 2016. However, 2017 saw a decline in the tonnage of demolished ships. The volumes have remained promising for the industry.

Figure 2 shows that China accounts for approximately $15 \%$ of demolitions, while the subcontinent, consisting of India, Pakistan, and Bangladesh, accounts for approximately 


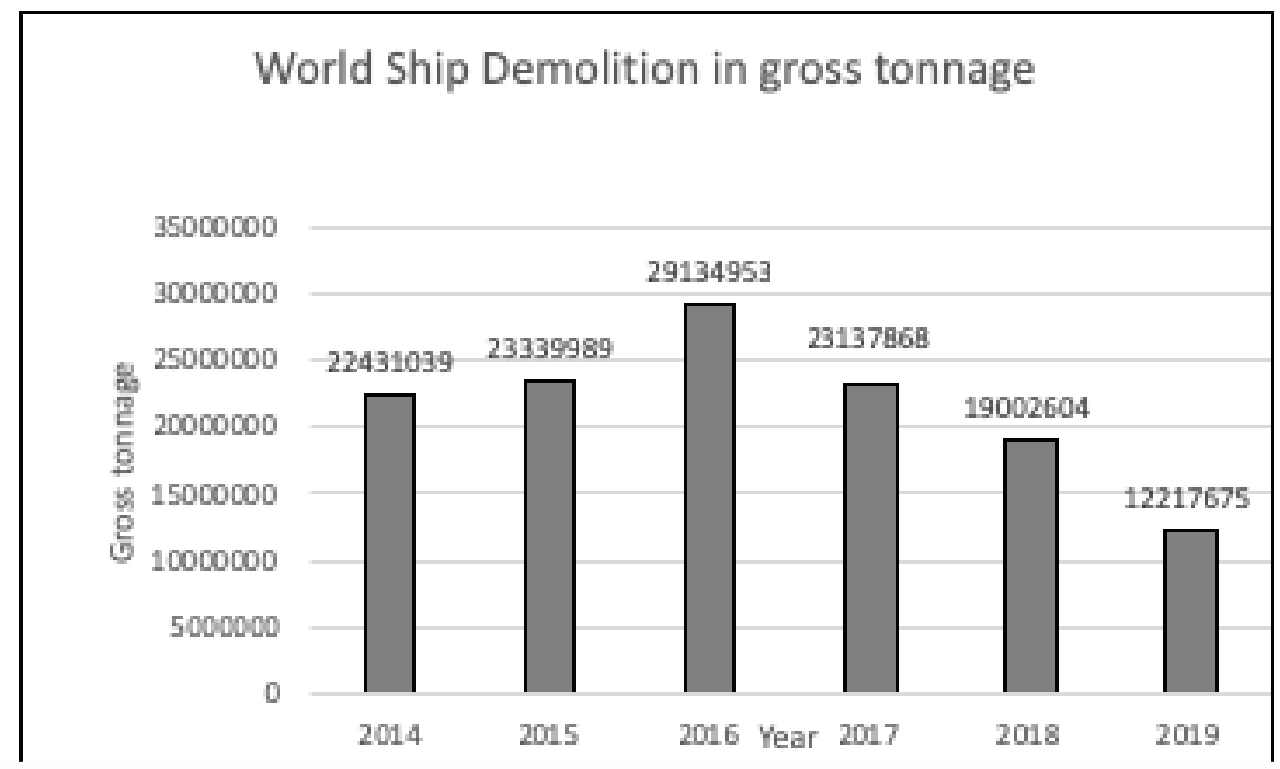

Figure 1.

World ship demolition in gross tonnage.

\section{Share of Ship Demolition by Asian Countries}

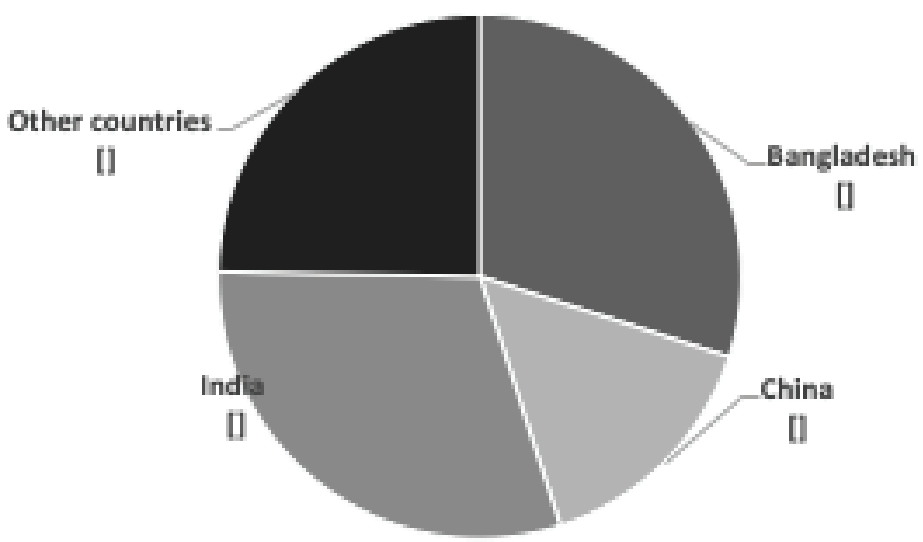

Figure 2.

Ship demolition by Asian countries. 


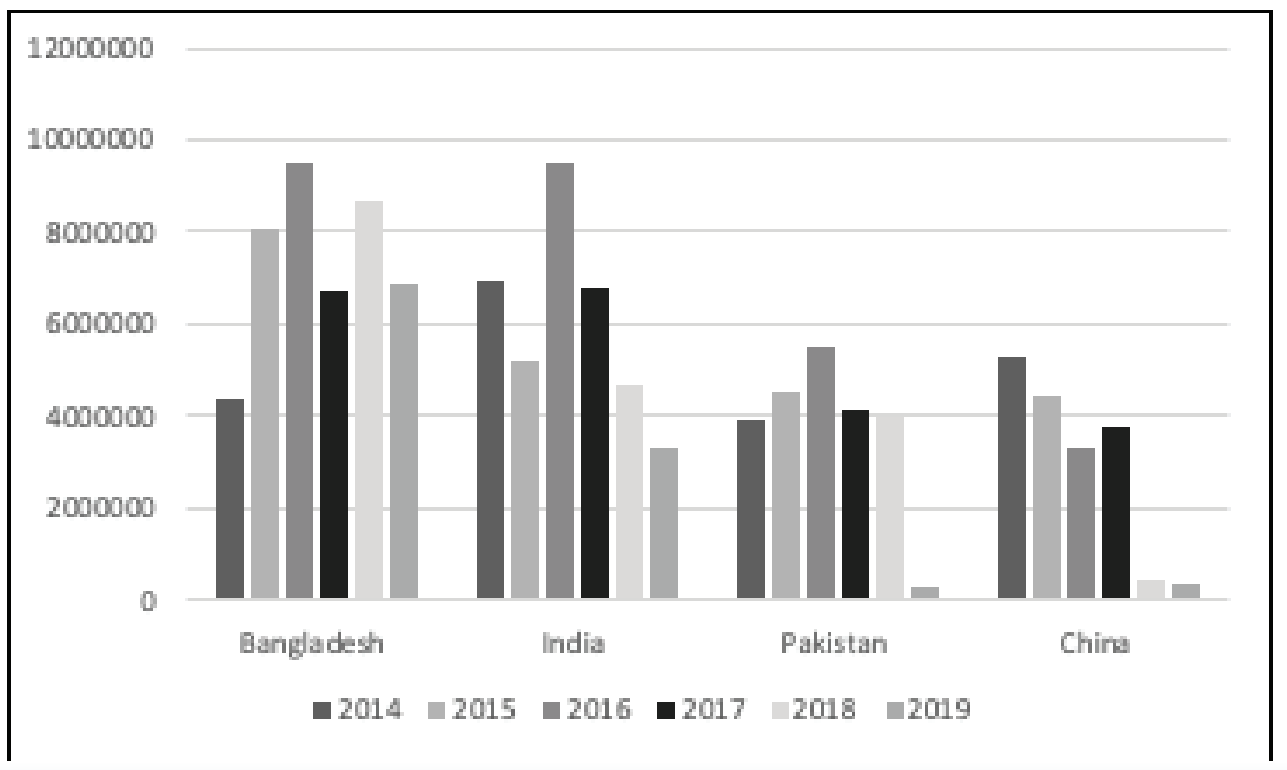

Figure 3.

Increase in the gross tonnage of demolished ships in top four countries.

$60 \%$. Figure 3 illustrates growing demolition volumes in India, Pakistan, and Bangladesh. India and Bangladesh are shown to have experienced satisfactory growth except in 2017.

Having gained an understanding of the market share of various countries in ship demolition over the last four years, we chose China and the subcontinent as two major markets to be targeted by our study. We are yet to understand the relationship between the two markets, even though volumes are quite promising.

According to (UNCTAD, 2017) four countries - India, Bangladesh, Pakistan, and China - account for 94.9 per cent of known ship scrapping. Turkey managed to keep the market niche of gas carrier, ferry and passenger ship scrapping. All other countries combined account for only 1.6 per cent of the world's total. The report shows that the gross tonnage of demolished ships in 2017 decreased by one quarter compared to 2016, which is an indicator of improved market optimism. Though bulk carrier and container ship scrapping slowed down in response to improved market conditions, tanker recycling increased. The study is quite distinctive as there is little understanding of the relationship between the two demolition indices. The majority of ship scrapping continued to take place in India, followed by Bangladesh and Pakistan. This paper attempts to understand the volatility, leverage effects and causality relationships between the two Baltic Demolition indices.

\section{LITERATURE OVERVIEW}

Little has been written about the ship demolition market, a fundamental component in the shipping supply/demand ratio. Only a limited number of studies examined the economic and econometric models in the ship demolition and recycling domain. Research papers and reports referred to in this section are presented in chronological order. The working report by (Stuer-Lauridsen, Kristensen, \& Skaarup Cowi, 2003) discusses various driving instruments of the shipbreaking process and gives an account of the environmental consistency of select offices of OECD nations which might be utilized to scrap ships secured by Danish controls.

All shipbreaking takes place in Asia, especially in Pakistan, India, Bangladesh and China. Ship owners find scrap ship rates offered by shipbreakers from those countries (exceeding OECD rates by up to two times) attractive. Consequently, only a limited number of shipyards in OECD countries still provide shipbreaking services. The reasonable limits of Canada, France, Germany, the UK, and other OECD nations have not been researched due to the absence of shipbreaking records. Similarly, the USA was excluded, although experts in charge of obsolete navy vessels have authorized four US organizations for dispatch rejection. The Mexican shipbreaking industry has downscaled in the last decade. In (Ea Krogstrup, 2006), the authors discus political 
and environmental issues relevant to various ship scrapping stakeholders. The thesis examines whether ships are considered products or waste at the time of scrapping, which depends on the policies of various countries and the International Maritime Organization. The initial market analysis of ship demolition has been discussed in (Buxton, 1991). The author has brought forward various elements of the purchase and sale of ships. Economic obsolescence, affected by freight market levels, seems to be a significant factor in ship scrapping. The cost of ship demolition and the realizable value of materials have an effect on the choice of the country of demolition. The paper analyses the trend based on data from the 1960s, when the shipbreaking market was shifting from Taiwan and western Europe to the Indian subcontinent. In (Kaiser, 2008) Mark Kaiser discusses ship and rig scrapping in the American Gulf of Mexico. The paper also reviews factors that have an impact on disposal and shipbreaking costs.

An early attempt at econometric modelling in the ship demolition market was made in (Knapp, Kumar, \& Remijn, 2008). The aim of econometric analysis was to understand the dynamics of the ship demolition market. The results indicate the positive effect on ship scrap prices and negative effect on ship earnings. Of all countries, Bangladesh was found to be the most sensitive to ship scrap prices, followed by India, Pakistan and Turkey. Other variables like ship age, ownership, flag of registration and profile were also analyzed. The system dynamic approach was used in (Kusumaningdyah, Eunike, \& Yuniarti, 2013) to gain an understanding of the economic benefits and environmental losses attributable to the shipbreaking industry. The impact of shipbreaking activity on the environment, health and safety in Bangladesh was studied in (Hossain, Fakhruddin, Chowdhury, \& Gan, 2016). Effective management practices and adequate planning are required to mitigate environmental impacts, and improve the health and safety of workers. In addition, the issues and challenges relating to fatal accidents during ship demolition in Bangladesh were discussed in (Rabbi \& Rahman, 2017).

The effect of foreign exchange rates on ship demolition was studied in (Karlis, Polemis, \& Georgakis, 2016). The results indicate a strong correlation between foreign exchange rates and ship scrap prices. Karlis also explained how money flows are affected by currency fluctuations in (Karlis \& Polemis, 2016). Ship demolition market forecasting and modelling was conducted in (Nikos D. Kagkarakis, Andreas G. Marikas, 2016). The correlation between international steel scrap prices and ship demolition was established using the Vector Autoregressive model (VAR). The model was applied to south Asian countries which depend on steel scrap importation and are experiencing growing ship demolition activity. The impact of various factors like less efficient ships, financial crisis, etc. on ship demolition in different market conditions has been analyzed using the survival distribution function in (Yin \& Fan, 2018).
The above overview clearly shows that only a limited number of studies have tried to explain the volatility of ship demolition indices and that econometric analysis in this area is scarce. Therefore, there is a need to explore the volatility of ship demolition indices.

\section{RESEARCH METHODOLOGY}

The time series are initially tested for unit root by using the Augmented Dickey-Fuller test (David A. Dickey and Wayna A. Fuller, 1981). The volatility of both indices was determined using the EGARCH model (Nelson, 1991). The EGARCH $(1,1)$ model is given below.

$\log \left(\sigma_{t}^{2}\right)=a_{0}+\left[1-\beta_{1}\right]^{-1}\left[1+a_{1}\right] \gamma z t_{-1}$

Where $\sigma_{t}^{2}$ is conditional and $z(t)$ residual volatility.

$a_{0}=$ constant in the variance equation, $a_{1}=\mathrm{ARCH}$ parameter, $\beta_{1}=$ GARCH parameter and

$\gamma=$ asymmetry parameter.

As an extension of the study, we also explored whether there was any spillover between the two markets. We used the Granger Causality test (C. W. J. Granger, 1969). However, as the test established the presence of spillovers, an extensive study on spillovers should be conducted separately.

\section{DATA}

Two time series (Baltic Exchange limited, 2019) have been analyzed in this paper:

Weekly Baltic China index rates for bulk carriers of per long ton displacement between $7000 \mathrm{dwt}$ and $12000 \mathrm{dwt}$ lightweight from 07/01/2008 to 17/09/2018 - 552 observations.

Weekly Baltic Subcontinent index rates for bulk carriers of per long ton displacement between $7000 \mathrm{dwt}$ and $12000 \mathrm{dwt}$ lightweight from 07/01/2008 to 17/9/2018 - 552 observations.

\section{ANALYSIS}

We estimated the volatility of ship demolition index rates in China and the Indian subcontinent (India, Pakistan, and Bangladesh). The data have a weekly frequency, and span the period from the first week of January 2007 to the third week of September 2018 (552 observations). We used logarithmic differences for our analytical purposes. First, we estimated the summary statistics for both series. The results are given in Table 1. The results indicate that both series are negatively skewed and exhibit fat-tails. This finding is corroborated by JB statistics that confirm the non-normal distributional nature of both series. 
Table 1.

Summary statistics.

\begin{tabular}{lllll} 
Parameters & China & P-values & Subcontinent & P-values \\
\hline minimum & -0.09396 & & -0.14709 & $-7.79 \mathrm{E}-05$ \\
\hline mean & -0.00036 & & 0.048919 & \\
\hline maximum & 0.095947 & & 0.013506 & 0.000 \\
\hline Standard deviation & 0.013188 & & -4.3865 & 0.000 \\
\hline Skewness & -0.781 & 0.000 & 40.812 & 0.000
\end{tabular}

\section{EGARCH ANALYSIS}

We have used conditional volatility models from the GARCH family. The GARCH model was introduced by Engle and Bollerslev (Engle \& Bollerslev, 1986). GARCH family models assume that volatility has a specific functional form are therefore called conditional volatility models. GARCH models are classified based on the functional form of volatility and require that the data used in the model be stationary.

Consequently, we applied the Augmented Dicky Fuller (ADF) (David A. Dickey and Wayna A. Fuller, 1981) test on the log differenced series. The results are given in Table 2 .

Table 2.

Unit root test results

\begin{tabular}{lll} 
Series & Statistic & P-values \\
\hline China & -12.882 & 0.000 \\
\hline Indian subcontinent & -11.324 & 0.000 \\
\hline
\end{tabular}

Table 3.

Pre-estimation diagnostics.
In the ADF test, the null hypothesis is that there is a unit root present in the data, i.e. the series is non-stationary. The unit root test results clearly show that the null of unit root is rejected for both series, implying that both series are stationary. Therefore, it is safe to proceed with volatility modeling. Before attempting conditional volatility modeling, we need to establish whether the dataset exhibits autocorrelation and volatility clustering. We thus estimated the Ljung-Box Q statistic (BOX, 1978) for autocorrelation for the standardized squared residuals and the ARCH-LM test (Engle, 1982) for volatility clustering. The results are presented in Table 3 . The results of the Ljung-Box test suggest that the null hypothesis that there is no autocorrelation is rejected for both series. Similarly, the null hypothesis that there is no volatility clustering is rejected for both India and the subcontinent in the ARCH LM test results.

The pre-estimation diagnostic test results indicated the presence of conditional volatility in the data. We then proceeded with GARCH model estimation. We used Exponential GARCH, a.k.a EGARCH (Nelson, 1991) model to estimate the conditional volatility present in the dataset. EGARCH was selected because (a) it is not limited by the positivity constraints of GARCH models, (b) EGARCH can distinguish the impact of negative news and

\begin{tabular}{lllll} 
Tests & China & P-values & Subcontinent & P-values \\
\hline LB( $\left.\mathrm{Q}^{2}\right)[5]$ & 13.745 & 0.000 & 67.088 & 0.000 \\
\hline ARCH LM [5] & 97.1952 & 0.000 & 275.789 & 0.000 \\
\hline
\end{tabular}




\section{GRANGER CAUSALITY TEST RESULTS}

We examined whether there is any causal relationship between ship demolition rates in China and the Indian subcontinent by using the Granger causality test (C. W. J. Granger, 1969). Granger causality can be interpreted as a test of predictive ability. Consider two series, $\mathrm{X}$ and $\mathrm{Y}$. The $\mathrm{X}$ series granger causes $Y$ if $Y$ can be better predicted by using the values of $X$ along with the lagged values of $Y$.

While interpreting the results, it must be noted that the Granger causality test is a test of predictive ability rather than a test of actual causality. The Granger causality requires both series analyzed to be stationary. As they have previously been tested for stationarity by unit root testing, this criterion is met. The results of the Granger causality test for ship demolition rates in China and the Indian subcontinent are given in Table 6. The Granger test's optimal lag length was determined using the AIC (Akaike Information Criteria) values and was found to be 3 .

Table 6

Granger Causality test results

\begin{tabular}{lll} 
Hypothesis & Statistic & P-values \\
\hline China(NGC)Subcontinent & 5.0658 & 0.001 \\
\hline Subcontinent(NGC)China & 7.464 & 0.000 \\
\hline Note: NGC stands for "Not Granger Causes." \\
\hline
\end{tabular}

Bidirectional causality between China and India was examined. The null hypothesis is that $X$ does not granger cause $Y$ and vice versa. Granger causality test results indicate that the null of no Granger causality should be rejected in both cases. Therefore, we have evidence of existence of a bidirectional causal relationship, i.e. evidence that ship demolition rates of China and the Indian subcontinent influence each other.

\section{CONCLUSIONS}

The ship demolition segment is hugely important in the maritime domain and responsible for active fleet supply stabilization. The decision to scrap a ship depends on a number of elements, such as ship age and obsoleteness, amendments to maritime and environmental regulations, as well as circumstances in the maritime domain. Under the worst conditions, even ships as young as ten years are sent to the scrapyard to ensure continued balance on the market and the survival of ship owners in bad times. The decision is dependent upon ship demolition prices. The analysis performed in this study propounds essential knowledge of the ship demolition segment, which is different from what was done in earlier studies. In this research, time series were first tested for unit root by using the Augmented Dickey-Fuller test, followed by the establishment of the volatility of both indices with the EGARCH model. The foremost aim of this study was to estimate the volatility of ship demolition index rates for China and the Indian subcontinent (India, Pakistan, and Bangladesh) to allow ship owners to pick the appropriate time and price of ship demolition. A thorough overview of literature has shown that a study of this type was long awaited. In the developing economies the increasing need for a comfortable life is counterbalanced by growing unemployment. For developing countries with a vast population and growing demand the ships demolition business is of great interest since materials ranging from steel, engines and toilets can be put into use. Also, the costs of labor are meagre compared to those in the developed economies. Moreover, ship demolition activities are a major source of environmental pollution as large quantities of carcinogens and toxic materials are emitted which are not only dangerous for workers but also increase the acidity of soil and coastal waters. For all these reasons, developed countries have banned ship demolition activities. Based on years of observation of trends in all countries we came to the conclusion that the five leading countries in the ship demolition business are India, Bangladesh, Pakistan, China and Turkey. Given that these countries are dominating the ship demolition market, we decided to take a closer look at the relationship between the markets of China and the subcontinent to help vessel owners choose the most favourable ship demolition region. The analysis of the first objective has shown that ship demolition indices are volatile and asymmetric by nature. Vessel owners should thus make timely decisions should they decide to demolish their ships in either of these regions. The Granger Causality Test helped us find evidence of bidirectional causality between the two ship demolition indices, implying that the ship demolition rates of China and the subcontinent influence each other. This implies that whenever vessel owners are thinking about ship demolition, they have to consider both these markets before making their final decision, as one affects the other. Owing to the recession of 2008-09 and its impact in the following years, some ship owners worldwide opted to demolish younger, but unemployed fleet for cash. China and the sub-continent are the leading ship demolition markets and hence volatile. Therefore, if vessel owners are deciding which market to choose for demolition, they must consider both due to their bi-directional mutual influences. They can never make this decision focusing on a single index series; both must be taken into account if they want their decision to be sound. This analysis is a brief insight into demolition considerations that individual ship owners should keep in mind and is intended to help shipping companies, primarily smaller entities, to make profitable scrapping decisions. This study will also contribute to 
the ship owners' understanding of the volatility and correlation between ship demolition rates at the global level, helping them reap the benefits of more favorable demolition rates.

\section{REFERENCES}

Baltic Exchange limited, 2019. Market Information. Retrieved September 30, 2019, from Daily independent shipping market information website: https://www. balticexchange.com/en/data-services/market-information0.html.

Buxton, I.L., 1991. The market for ship demolition. Maritime Policy \& Management, 18(2), pp.105-112. Available at:

http://dx.doi.org/10.1080/03088839100000034

Dickey, D.A. \& Fuller, W.A., 1981. Likelihood Ratio Statistics for Autoregressive Time Series with a Unit Root. Econometrica, 49(4), p.1057. Available at: http://dx.doi.org/10.2307/1912517.

Ea Krogstrup, K. K. N. A., 2006. Ship Scrapping - a Floating Scenario. University of Roskilde, Denmark.

Engle, R.F. \& Bollerslev, T., 1986. Modelling the persistence of conditional variances. Econometric Reviews, 5(1), pp.1-50. Available at: http://dx.doi.org/10.1080/07474938608800095.

Engle, R.F., 1982. Autoregressive Conditional Heteroscedasticity with Estimates of the Variance of United Kingdom Inflation. Econometrica, 50(4), p.987. Available at: http://dx.doi.org/10.2307/1912773.

Granger, C.W.J., 1969. Investigating Causal Relations by Econometric Models and Cross-spectral Methods. Econometrica, 37(3), p.424. Available at: http://dx.doi.org/10.2307/1912791.

Hossain, M.S. et al., 2016. Impact of ship-Breaking activities on the coastal environment of Bangladesh and a management system for its sustainability. Environmental Science \& Policy, 60, pp.84-94. Available at: http://dx.doi.org/10.1016/j.envsci.2016.03.005.

Kagkarakis, N.D., Merikas, A.G. \& Merika, A., 2016. Modelling and forecasting the demolition market in shipping. Maritime Policy \& Management, 43(8), pp.10211035. Available at:

http://dx.doi.org/10.1080/03088839.2016.1185181.
Kaiser, M.J., 2008. A Review of Ship Breaking and Rig Scrapping in the Gulf of Mexico. Ocean Development \& International Law, 39(2), pp.178-199. Available at: http://dx.doi.org/10.1080/00908320802013701.

Karlis, T. \& Polemis, D., 2016. Ship demolition activity. Pomorstvo, 30(2), pp.128-132. Available at:

http://dx.doi.org/10.31217/p.30.2.5.

Karlis, T., Polemis, D., \& Georgakis, A., 2016. Ship demolition activity. An evaluation of the effect of currency exchange rates on ship scrap values. Journal of Economics and Business, 66(3), pp. 53-70.

Knapp, S., Kumar, S.N. \& Remijn, A.B., 2008. Econometric analysis of the ship demolition market. Marine Policy, 32(6), pp.1023-1036. Available at: http://dx.doi.org/10.1016/j.marpol.2008.02.004.

Kusumaningdyah, W., Eunike, A. \& Yuniarti, R., 2013. Modeling Tradeoff in Ship Breaking Industry Considering Sustainability Aspects: A System Dynamics Approach. Procedia Environmental Sciences, 17, pp.785-794. Available at: http://dx.doi.org/10.1016/j.proenv.2013.02.096.

Ljung, G.M. \& Box, G.E.P., 1978. On a measure of lack of fit in time series models. Biometrika, 65(2), pp.297-303. Available at: http://dx.doi.org/10.1093/biomet/65.2.297.

Nelson, D.B., 1991. Conditional Heteroskedasticity in Asset Returns: A New Approach. Econometrica, 59(2), p.347. Available at: http://dx.doi.org/10.2307/2938260.

Rabbi, H.R. \& Rahman, A., 2017. Ship Breaking and Recycling Industry of Bangladesh; Issues and Challenges. Procedia Engineering, 194, pp.254-259. Available at: http://dx.doi.org/10.1016/j.proeng.2017.08.143.

Stuer-Lauridsen, F., Kristensen, N., \& Skaarup Cowi, J. A., 2003. Shipbreaking in OECD. Retrieved from http://www.shipbreakingplatform.org/shipbrea_wp2011/ wp-content/uploads/2013/03/Shipbreaking-in-OECD-Cowi-2003.pdf.

UNCTAD, 2017. Review of Maritime Transport 2017. Review of Maritime Transport. Available at: http://dx.doi.org/10.18356/a9b345e7-en.

UNCTAD, 2019. Ship scrapping by country of demolition, annual report, 2014-2017.

Yin, J. \& Fan, L., 2018. Survival analysis of the world ship demolition market. Transport Policy, 63, pp.141-156. Available at: http://dx.doi.org/10.1016/j.tranpol.2017.12.019. 